\title{
Endoscopic combined "transseptal/transnasal" approach for pituitary adenoma: reconstruction of skull base using pedicled nasoseptal flap in 91 consecutive cases
}

\author{
O acesso endoscópico transeptal/transnasal em cirurgias de resseção de adenoma de \\ hipófise: reconstrução da base do crânio combinado com a criação do flap naso-septal \\ pediculado em 91 pacientes consecutivos
} Yasunori Fujimoto 1,2, Leonardo Balsalobre², Fábio P. Santos ${ }^{2}$, Eduardo Vellutini ${ }^{3}$, Aldo C. Stamm²

\begin{abstract}
Objective: The purpose of this study was to describe the endoscopic combined "transseptal/transnasal" approach with a pedicled nasoseptal flap for pituitary adenoma and skull base reconstruction, especially with respect to cerebrospinal fluid (CSF) fistula. Method: Ninety-one consecutive patients with pituitary adenomas were retrospectively reviewed. All patients underwent the endoscopic combined "transseptal/transnasal" approach by the single team including the otorhinolaryngologists and neurosurgeons. Postoperative complications related to the flap were analyzed. Results: Intra- and postoperative CSF fistulae were observed in 36 (40\%) and 4 (4.4\%) patients, respectively. Among the 4 patients, lumbar drainage and bed rest healed the CSF fistula in 3 patients and reoperation for revision was necessary in one patient. Other flap-related complications included nasal bleeding in 3 patients (3.3\%). Conclusion: The endoscopic combined "transseptal/transnasal" approach is most suitable for a two-surgeon technique and a pedicled nasoseptal flap is a reliable technique for preventing postoperative CSF fistula in pituitary surgery.
\end{abstract}

Keywords: cerebrospinal fluid fistula, endoscopic endonasal approach, pedicled nasoseptal flap, pituitary adenoma.

\section{RESUMO}

Objetivo: O objetivo deste estudo foi descrever o acesso endoscópico transeptal/transnasal combinado com a criação do flap nasoseptal pediculado para reconstrução da base do crânio em cirurgias de resseção de adenoma de hipófise, especialmente nos casos que ocorrem fístula líquido cefalorraquidiano (FLC). Método: Noventa e um pacientes consecutivos portadores de adenoma de hipófise foram retrospectivamente revisados. Complicações pós-operatórias relacionadas ao flap foram analisadas. Resultados: Fístulas líquido cefalorraquidiano intra e pós-operatórias foram observadas em 36 (40\%) e 4 (4,4\%) dos pacientes, respectivamente. Entre os 4 pacientes, drenagem lombar e repouso absoluto foram suficientes para o fechamento da fístula e intervenção cirúrgica foi necessária em apenas um paciente. Outra complicação relacionada ao flap foi o sangramento em 3 (3,3\%) dos pacientes. Conclusão: 0 acesso endoscópico transeptal/transnasal combinado é melhor aplicado quando realizado por dois cirurgiões e o flap naso-septal é uma técnica eficaz para prevenção de fístula pós-operatória em cirurgias de hipófise.

Palavras-chave: fístulas líquido cefalorraquidiano, acesso endoscópico endonasal, flap naso-septal pediculado, adenoma de hipófise.

Transsphenoidal surgery using a microscope is an established, less invasive surgery for pituitary adenomas. The advent of the endoscope for endonasal transsphenoidal surgery has provided a wider and more close-up panoramic view that has made more detailed, delicate procedures feasible and safer. Furthermore, recent advance in high definition (HD) imaging have made it possible to clearly differentiate a cleavage plane between a tumor and the cavernous sinus or the arachnoid membrane, likely contributing to improvements in patient outcomes. However, the

${ }^{1}$ Osaka Neurological Institute, Department of Neurosurgery, Toyonaka, Osaka, Japan;

${ }^{2}$ Complexo Hospitalar Edmundo Vasconcelos, São Paulo ENT Center, Sao Paulo SP, Brazil;

${ }^{3}$ DFV Neuro, Sao Paulo SP, Brazil.

Correspondence: Yasunori Fujimoto; Department of Neurosurgery, Osaka Neurological Institute; 2-6-23, Shonai Takara-machi, Toyonaka, Osaka 561-0836, Japan;E-mail:yasufujimoto@gmail.com

Conflict of interest: There is no conflict of interest to declare.

Received 08 January 2015; Received in final form 06 February 2015; Accepted 26 February 2015. 
postoperative cerebrospinal fluid (CSF) fistula still remains a serious and frequent complication, causing meningitis, abscess and pneumoencephalus ${ }^{1,2}$.

There have been many reports describing methods and strategies for reconstruction of a dural defect in the sellar floor and the skull base $e^{2,3,4,5,6,7,8}$. The utility of a pedicled nasoseptal flap ${ }^{9}$ for the reconstruction of a large dural defect has recently become more widely accepted, but reports have included a variety of pathologies, approaches and reconstruction techniques ${ }^{6,8,10}$. To minimize the risk of postoperative CSF fistula, we have used a pedicled nasoseptal flap for pituitary adenomas, as well as for skull base tumors ${ }^{11,12}$. We describe our strategy for surgical management of pituitary adenomas via combined endoscopic "transseptal/transnasal" approach that provides a pedicled nasoseptal flap. We discuss the availability of the flap for reconstruction and flap-related complications.

\section{METHOD}

This study was approved by the Complexo Hospitalar Edmundo Vasconcelos Institutional Review Board. Ninety-one consecutive patients (92 surgeries) of pituitary adenomas treated between January 2007 and February 2011 via an endoscopic combined "transseptal/transnasal" approach with a pedicled nasoseptal flap were retrospectively reviewed. All patients were treated using similar procedures by the same surgical team, which included otorhinolaryngologists and neurosurgeons. The patients, whose follow-up period was over one year, were 47 men and 44 women, with ages ranging from 22 to 82 years old (mean 45.9). Among the 91 pituitary adenomas, 23 were growth hormone-secreting, 6 were prolactin-secreting, 5 were adrenocorticotropic hormone-secreting and 57 were nonfunctioning adenomas. All 34 functioning adenomas were microadenomas and the others were macroadenomas. Eight patients had undergone previous surgeries, including transsphenoidal surgery in five patients, craniotomy in two patients, and both in one patient. Data collected included observation of intraoperative CSF fistula, and postoperative complications including CSF fistula, epistaxis, septal perforation and crusting.

\section{Surgical technique}

The surgical technique presented here is modified from one described earlier by the authors ${ }^{11}$. An endoscopic combined "transseptal/transnasal" approach is performed under general anesthesia using both 0 - and 45-degree endoscopes with a diameter of $4 \mathrm{~mm}$ (Karl Storz, Tuttlingen, Germany). Nasal mucosa in the surgical corridor was decongested with cottonoids containing epinephrine in a 1:2,000 dilution. The septum was infiltrated with $1 \%$ lidocaine with epinephrine in a 1:100,000 dilution. The middle turbinates were compressed and outfractured laterally at the base. A nasal septal hemitransfixion incision was performed unilaterally, usually on the right side, and sub-perichondrial/periosteal dissection was performed, reaching the anterior wall of the sphenoid sinus. A vertical incision of the cartilage $1 \mathrm{~cm}$ posterior from the anterior limit was made and a contralateral sub-perichondrial/periosteal dissection was also performed. The cartilage was cut off at $1 \mathrm{~cm}$ from the anterior and 1 $\mathrm{cm}$ from the superior limit of the septum, preserving the 'L'-shaped strut of the cartilage. The bony septum was also removed, leaving the inferior portion as a midline landmark. Subsequently a pedicled mucoperichondrial/mucoperiosteal flap based on the sphenopalatine artery was elevated on the opposite side. The septal mucosa was cut along the contour of the septal defect superiorly along the line connecting the inferior aspect of the sphenoid ostium, and inferiorly along the line following the maxillary crest. As a result, the mucosa $1 \mathrm{~cm}$ from the most anterior and $1 \mathrm{~cm}$ from the most superior aspect of the nasal septum remained intact. This "L"-shaped cut of the septum and mucosa resulted in both preservation of olfactory function and avoidance of a saddlenose deformity. The flap was rotated caudally and stored in the nasopharynx so as not to be damaged during the tumor removal. The sphenoid ostia were enlarged and the sphenoid sinus was opened widely (Figure 1A). Consequently, a binostril approach through one cavity combining transseptal with transnasal routes was accomplished without posterior septal perforation.

Drilling of the sellar floor with high-speed drill was performed and the floor was thinned down to "egg-shell" thickness and then removed with a Kerrison rongeur to the cavernous sinuses bilaterally (Figure 1B). Bone removal could be done to the tuberculum sellae depending on the degree of anterior extension of the tumor. The dura mater was cut in rectangular fashion and removed ${ }^{13}$. Meticulous dissection of the tumor from the cavernous sinus walls laterally or the arachnoid membrane superiorly proceeded with a two-surgeon and four-handed technique, namely, one surgeon handled an endoscope and a dissector while a second surgeon provided suction and held a forceps. This technique used a high definition (HD) video system, so extracapsular total resection of the tumor was possible, and radical resection could be done even in a tumor extending to the cavernous sinus (Figure 1C).

\section{Reconstruction}

When intraoperative CSF fistula had not been identified, Gelfoam (Pfizer, New York, NY, USA) or Surgicel ${ }^{\circ}$ (Ethicon Inc, Johnson \& Johnson Company, Somerville, NJ, USA) was placed in the sella and the sellar floor was covered with a pedicled nasoseptal flap and adhered tightly to the dura mater and the surrounding bony surface (Figure 1D, Figure 2). Absorbable hemostatic gelatin powder, Surgiflo or Spongostan powder (Ethicon Inc, Johnson \& Johnson Wound Management, Somerville, NJ, USA) and Gelfoam 

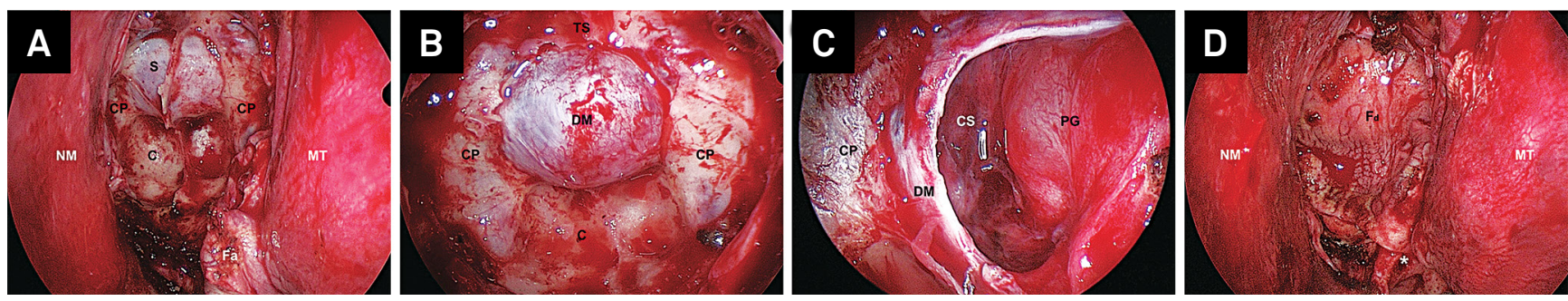

C: clivus; CP: carotid protuberance; CS: medial wall of the right cavernous sinus; DM: dura mater; Fa: pedicled nasoseptal flap stored into the nasopharynx; Fd: pedicled nasoseptal flap covering the sellar floor; MT: left middle turbinate; NM: reverse side of the right nasal mucosa; PG: pituitary gland; S: sellar floor; TS: tuberculum sellae.

Figure 1. Intraoperative endoscopic view. A: The surgical field after the sphenoidotomy, created using a binostril combined approach with the right transseptal and left transnasal approaches. B: A panoramic view of the sphenoid sinus after removal of the sellar floor. A craniectomy of the sellar floor is performed up to the limit of the cavernous sinus laterally and the tuberculum sellae superiorly. C: A close-up view of the right sellar cavity after removal of a tumor. The medial wall of the right cavernous sinus is observed using a 0 degree endoscope. D: After the placement of the flap over the sella. The pedicled nasoseptal flap covered the entire posterior wall of the sphenoid sinus. The asterisk indicates the pedicle of the flap.

were layered directly over the flap. The flap was supported by Rapid Rhino (ArthroCare Corporation, Austin, TX, USA). When intraoperative CSF fistula had been identified, the "triple F” reconstruction ( fat, fascia and flap) was preferred, i.e., the dead space was filled with a free fat graft and a piece of fascia lata inlay graft was inserted. Then the dural defect together with sellar floor was covered with the flap. Hemostasis on the mucosa and bone was confirmed to avoid postoperative bleeding. Neither fibrin glue nor lumbar drainage was used routinely.

\section{Postoperative care}

Intravenous administration of antibiotics was started at the beginning of surgery and continued postoperatively while nasal packing remained in situ. Computed tomography imaging was performed on the first postoperative day to check for evidence of hemorrhage. When intraoperative CSF fistula had been observed, the patients were placed on bed rest with 30 degrees of head elevation for 48 hours, to avoid straining, Valsalva maneuvers and nose blowing. Nasal packing was left in place for approximately 3 days. Lumbar drainage was not routinely used unless there was intracranial hypertension or prior radiotherapy. When postoperative CSF fistula occurred, it was managed by lumbar drainage or reoperation. Discharge was usually allowed on postoperative days 3 to 5 . Postoperative intranasal care was mandatory and the patients were cared on outpatient basis at least 5 visits; on 7,14 , 30, 60 and 90 days after surgery. They were instructed to wash the nose with saline three times a day in the first month.

\section{RESULTS}

Figure 3 shows the results concerning CSF fistula. Out of 91 patients with pituitary adenomas, intraoperative CSF fistula was observed in 36 patients (40\%). Postoperative CSF fistula occurred in 4 patients with macroadenoma, all of

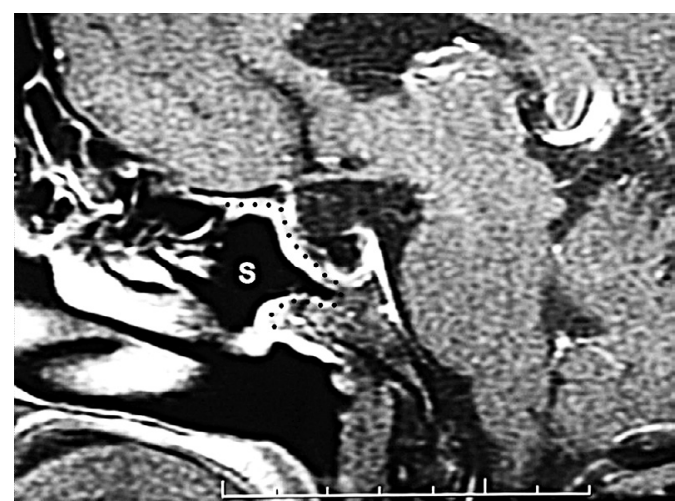

S: sphenoid sinus.

Figure 2. Postoperative sagittal magnetic resonance image after administration of gadolinium. The dotted line shows the pedicled nasoseptal flap covering the sellar floor entirely and adhering tightly to the bone.

which cases had presented intraoperative CSF fistula. The rate of postoperative CSF fistula was 4.4\% (4/91) of all patients and $11 \%(4 / 36)$ of intraoperative CSF fistula patients. Among the 4 patients with postoperative CSF fistula, lumbar drainage and bed rest was prescribed for 3 days and healed the CSF fistula in 3 patients. Reoperation for revision was necessary in only one patient. The patient who underwent a revision surgery had three previous operations including a transsphenoidal surgery and two craniotomies. The other three patients with postoperative CSF fistula were those with macroadenoma and high flow CSF leak had occurred through laceration of the arachnoid membrane. We found that main cause of flap failure was the lack of adhesion between the flap and denuded bone around the dural defect. Other flap-related complications included delayed nasal bleeding in 3 patients (3.3\%; bleeding from the ethmoid artery in one, and from the septal branch of the sphenopalatine artery in 2 patients) and novel septal perforation in 4 patients (4.4\%). Nasal bleeding required hemostasis by electrical cauterization. The nasal crusting of the donor side of 


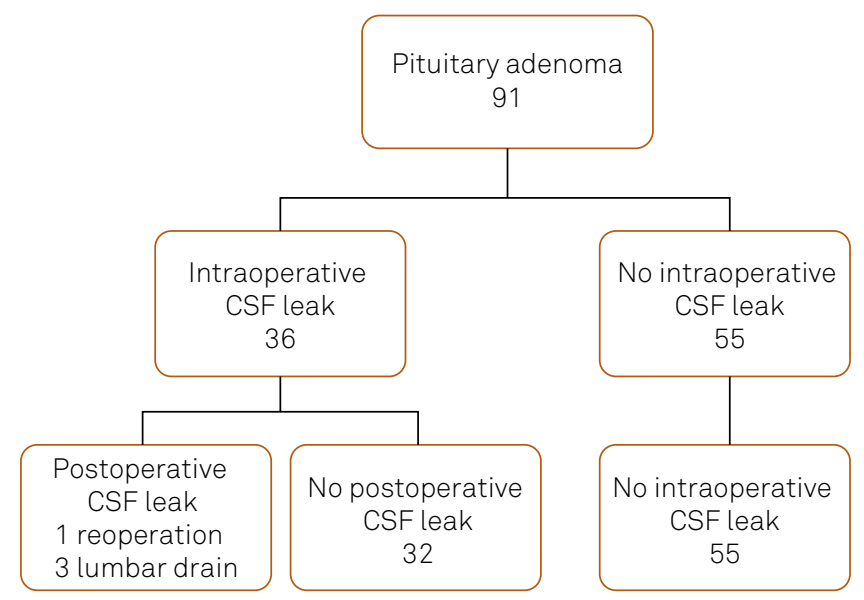

Figure 3. Results of this study concerning cerebrospinal fluid fistula.

the flap persisted approximately for 8 weeks after surgery. There were no infectious complications.

\section{DISCUSSION}

A variety of techniques with different autologous tissues and/or synthetic materials have been described for reconstruction of the sella after resection of pituitary adenomas using a transsphenoidal approach ${ }^{1,2,3}$. The introduction of the endoscope heralded a new era in modern pituitary surgery; however, postoperative CSF fistula have remained a serious complication, at a rate of $0-27 \%^{1,14}$. The results of a recent meta-analysis revealed a pooled rate of $2 \%^{14}$. Various reports have demonstrated good results for prevention of postoperative CSF fistula using an endoscopic approach ${ }^{2,3,4,5,7,14}$. However, most of the reports included various pathologies and origins of the CSF leak; for example, pituitary adenomas, craniopharyngiomas, meningiomas and malignant tumors, which were operated through different surgical approaches, and various strategies were applied for prevention of CSF fistula ${ }^{2,45,7}$. Furthermore no studies have directly compared these strategies. Some authors have described their own protocols for reconstruction of the sella according to the tumor extension or intraoperative findings ${ }^{2,3,4,5,8}$; however, the pedicled nasoseptal flap was not included as an option in these other protocols. Since Hadad et al. ${ }^{9}$ described vascular pedicle nasoseptal flap as a novel reconstruction technique in 2006 (Hadad-Bassagasteguy flap; HBF), it has been reported that this flap can function well to separate the intradural space from the nasosinusal cavity ${ }^{6,10,11,12,15}$. They reported a $4.7 \%$ rate of postoperative CSF fistula in a sample of 43 patients including 20 pituitary adenomas, all of which had presented intraoperative CSF fistula and required reoperations ${ }^{9}$. Kassam et al. ${ }^{10}$ also demonstrated the reliability of HBF for repairing defects of the skull base. They reported a $10.66 \%$ rate of postoperative CSF fistula in patients who required intra-arachnoidal dissection, and that the success of the HBF was associated with learning curve.

We applied a combined transseptal/transnasal approach as described above for the present series of pituitary adenomas ${ }^{11}$. This technique allows two surgeons not only to perform binostril work in a wide single surgical field but also to harvest a pedicled nasoseptal flap together. In addition, this does not cause a posterior septal perforation and an exposure of the denuded septal cartilage causing a persistent crusting, which are inevitable drawbacks of the original HBF technique. The pedicled nasoseptal flap can avoid lumbar drainage that may increase the chances of deep venous thrombosis due to days of bed rest, and the implant of synthetic materials for reconstruction that will persist as foreign bodies in the patients. Cappabianca et al. ${ }^{4}$ reported the rate of intraoperative and postoperative CSF fistula at $14.1 \%$ (21 patients) and $2.3 \%$ (4 patients), respectively, in 170 consecutive patients including 144 pituitary adenomas. They demonstrated that three of four patients with postoperative CSF fistula had not presented intraoperative CSF leak. Shiley et al. ${ }^{16}$ also reported a $4.0 \%$ incidence of postoperative CSF fistula in patients without intraoperative leaks. This may occur when a thin arachnoid membrane has ballooned out of the sella after the removal of macroadenomas, or when an undetected microscopic CSF leak occurs in microadenomas, resulting in an increased risk of high-volume CSF fistula. For these types of postoperative CSF fistula, reconstruction using the flap may reduce these risks. Furthermore, the flap technique may be useful also when the internal carotid artery has been exposed after the resection of adenoma extending to the cavernous sinus, or when postoperative irradiation may be planned ${ }^{1}$.

In the present study, we assume that the rate of postoperative CSF fistula was comparatively low, considering that the intraoperative CSF fistula rate was higher than in the previous reports ${ }^{4}$. This high incidence of intraoperative CSF fistula seems to be due to attempting radical resection of tumors and our ability to identify a small defect in the arachnoid membrane or a tiny CSF leak from unknown origin using the HD image. In fact, before we introduced this approach ${ }^{11}$, we had observed intraoperative CSF fistula in 15\% of cases and postoperative CSF fistula in $6.3 \%$ of patients out of a sample of 117 patients with pituitary adenomas (unpublished data). According to these data, our present study may demonstrate the efficacy of a pedicled nasoseptal flap in itself for reconstruction of the sella.

As for criticism that a pedicled nasoseptal flap would not be necessary or over-indicated for all cases of pituitary adenomas, we would emphasize that we intend to employ a twosurgeon and four-handed technique not only for skull base tumors but even for pituitary adenomas. Furthermore, the nasal crusting by our approach seemed to occur less seriously than by standard nasoseptal flap technique ${ }^{9,10}$, because the bone and cartilage of the septum was not exposed and mucosal re-epithelialization over the contralateral septal mucosa can be induced more rapidly than over the bone or cartilage. 
Nowadays in the case where the risk of postoperative CSF fistula may be low, we make a practice of repositioning and stitching a nasoseptal flap that has been once harvested onto the septum so as to reduce the crusting as much as possible. Our results suggest that even a pedicled nasoseptal flap technique cannot completely prevent postoperative CSF fistula after removal of pituitary adenomas. To achieve complete prevention of postoperative CSF fistula, a novel protocol for reconstruction of the sella, including a pedicled nasoseptal flap technique, may need to be established ${ }^{2}$.

In conclusion, the endoscopic combined transseptal/transnasal approach can provide a wide single surgical field for a two surgeon-technique and simultaneously facilitate the harvest of a pedicled nasoseptal flap for reconstruction of the sellar floor. Postoperative flap-related complications, including CSF fistula, occurred at an acceptably low rate. Development of endoscopic endonasal surgery has allowed radical resection of the lesions while using a less invasive procedure for the benefit of the patients. However, protocols need further development to reduce postoperative complications, especially CSF fistula. Based on the present study, the pedicled nasoseptal flap may be a reliable technique for reconstruction of a dural defect after resection of pituitary adenomas.

\section{References}

1. Ciric I, Ragin A, Baumgartner C, Pierce D. Complications of transsphenoidal surgery: results of a national survey, review of the literature, and personal experience. Neurosurgery. 1997;40(2):225-36 http://dx.doi.org/10.1097/00006123-199702000-00001

2. Tabaee A, Anand VK, Brown SM, Lin JW, Schwartz TH. Algorithm for reconstruction after endoscopic pituitary and skull base surgery. Laryngoscope. 2007;117(7):1133-7. http://dx.doi.org/10.1097/MLG.0b013e31805c08c5

3. Cappabianca P, Cavallo LM, Colao A, Divitiis E. Surgical complications associated with the endoscopic endonasal transsphenoidal approach for pituitary adenomas. J Neurosurg. 2002;97(2):293-8. http://dx.doi.org/10.3171/jns.2002.97.2.0293

4. Cappabianca P, Cavallo LM, Esposito F, Valente V, Divitiis E. Sellar repair in endoscopic endonasal transsphenoidal surgery: results of 170 cases. Neurosurgery. 2002;51(6):1365-72. http://dx.doi.org/10.1227/01.NEU.0000309112.17087.28

5. Esposito F, Dusick JR, Fatemi N, Kelly DF. Graded repair of cranial base defects and cerebrospinal fluid leaks in transsphenoidal surgery. Neurosurgery. 2007;60(4 suppl 2):295-304. http://dx.doi.org/10.1227/01.NEU.0000255354.64077.66

6. Zanation AM, Carrau RL, Snyderman CH, Germanwala AV, Gardner PA, Prevedello DM et al. Nasoseptal flap reconstruction of high flow intraoperative cerebral spinal fluid leaks during endoscopic skull base surgery. Am J Rhinol Allergy. 2009;23(5):518-21. http://dx.doi.org/10.2500/ajra.2009.23.3378

7. Romero AC, Nora JE, Topczewski TE, Aguiar PH, Alobid I, Rodriguéz EF. Cerebrospinal fluid fistula after endoscopic transsphenoidal surgery: experience in a spanish center. Arq Neuropsiquiatr. 2010;68(3):414-7. http://dx.doi.org/10.1590/S0004-282X2010000300017

8. Sciarretta V, Mazzatenta D, Ciarpaglini R, Pasquini E, Farneti G, Frank G. Surgical repair of persisting CSF leaks following standard or extended endoscopic transsphenoidal surgery for pituitary tumor. Minim Invasive Neurosurg. 2010;53(2):55-9. http://dx.doi.org/10.1055/s-0029-1246161
9. Hadad G, Bassagasteguy L, Carrau RL, Mataza JC, Kassam $\mathrm{A}$, Snyderman $\mathrm{CH}$ et al. A novel reconstructive technique after endoscopic expanded endonasal approaches: vascular pedicle nasoseptal flap. Laryngoscope. 2006;116(10):1882-6. http://dx.doi.org/10.1097/01.mlg.0000234933.37779.e4

10. Kassam AB, Thomas A, Carrau RL, Snyderman CH, Vescan A, Prevedello D et al. Endoscopic reconstruction of the cranial base using a pedicled nasoseptal flap. Neurosurgery. 2008;63(1 Suppl 1):ONS44-52. http://dx.doi.org/10.1227/01.neu.0000335010.53122.75

11. Stamm AC, Pignatari S, Vellutini E, Harvey RJ, Nogueira JF Jr. A novel approach allowing binostril work to the sphenoid sinus. Otolaryngol Head Neck Surg. 2008;138(4):531-2. http://dx.doi.org/10.1016/j.otohns.2007.11.031

12. Harvey RJ, Nogueira JF, Schlosser RJ, Patel SJ, Vellutini E, Stamm AC. Closure of large skull base defects after endoscopic transnasal craniotomy. Clinical article. J Neurosurg. 2009;111(2):371-9. http://dx.doi.org/10.3171/2008.8.JNS08236

13. Stamm AC, Pignatari SSN. Transnasal endoscopic-assisted surgery of the anterior skull base. In: Flint PW, Haughey BH, Lund VJ, Niparko JK, Richardson MA, Robbins KT et al., editors. Cummings Otolaryngology Head \& Neck Surgery. Philadelphia: Elsevier Mosby; 2010. p. 2471-86.

14. Tabaee A, Anand VK, Barrón Y, Hiltzik DH, Brown SM, Kacker A et al. Endoscopic pituitary surgery: a systematic review and meta-analysis. J Neurosurg. 2009;111(3):545-54. http://dx.doi.org/10.3171/2007.12.17635

15. Stamm AC, Vellutini E, Harvey RJ, Nogeira JF Jr, Herman DR. Endoscopic transnasal craniotomy and the resection of craniopharyngioma. Laryngoscope. 2008;118(7):1142-8. http://dx.doi.org/10.1097/MLG.0b013e318170b5dc

16. Shiley SG, Limonadi F, Delashaw JB, Barnwell SL, Andersen PE, Hwang PH et al. Incidence, etiology, and management of cerebrospinal fluid leaks following trans-sphenoidal surgery. Laryngoscope. 2003;113(8):1283-8. http://dx.doi.org/10.1097/00005537-200308000-00003 